\title{
The Wisdom of the New Era Is Still Shining: the Interpretation Based on Value Rationality
}

\author{
Liu Shulin \\ China Jiliang University \\ Hangzhou, Zhejiang, China
}

\begin{abstract}
Manjusri's great wisdom not only embraces the limited wisdom of the world, but also symbolizes the spirit of transcendence. This transcendental spirit enables human beings to evolve constantly, more in line with people's pursuit of value rationality, to make life moving, to make themselves strive to get rid of the short-lived and tend to be eternal, and to get rid of the finiteness and tend to be infinity. With the moral subject of outstanding standing, we can return to the human nature and self-improvement.
\end{abstract}

Keywords-Manjusri; Manjusri's wisdom; Value rationality; New era

\section{INTRODUCTION}

Buddhism, as many scholars believe, is a kind of philosophical wisdom with its own unique wisdom. Under the wisdom of Mahayana Buddhism, Manjusri's wisdom is particularly prominent. It is called "Great Wisdom Manjusri" and has become a representative and symbol of Buddhist wisdom. Manjushri as the left side of Sakyamuni Buddha, and the wisdom of the Lord, is also the representative of Buddha and the embodiment of Prajna. But many people only hear the name of Wisdom and Manjusri, but they don't know the truth of Manjusri. When we calm down and walk into this strange and mysterious world of Manjusri's thinking, we will find that although the wisdom of Manjusri is profound, it is mainly summarized as "prajna and wisdom" and "the second way". It is the essence of Manjusri wisdom and the wisdom of the Buddha; Manjushri can be said to be the user and communicator of Buddha's wisdom.

\section{INTRODUCTION TO MANJUSRI}

The academic circles have different academic concepts of it, such as Manjusri Wisdom and Manjusri Belief, to Manjushri. Among them, "Manjusri wisdom" has only been regarded as a new academic term in recent years, because Xiao Limin introduced a new research method combining the study of thought history and philosophical hermeneutics. The philosophical hermeneutics is mainly used to summarize the study of the method of the Manjusri.

Manjusri has a lot of identities, but it is generally named as the identity of Bodhisattva. There are two different understandings of Manjusri's identity: one is general common sense, which describes Manjusri is only the dojo in Wutaishan, Shanxi Province. He was one of the Bodhisattvas and one of the four great Buddhas of Buddhism, Bodhisattva, the
Sakyamuni Buddha's left-winged, represents wisdom and wisdom, "He is in purple gold, shaped like a boy, five crowns, his right hand holds a diamond sword, can kill the group of demons and solve all troubles, holding the blue lotus flower on the left, which has a diamond-like scroll, the mount is a lion." This tendency phenomenon is especially common in folk Buddhism; the second is complicated to the status of Manjushri. Identity, is a common tendency in the academic world, and a tendency to appear in academic research as well. For the Bodhisattva identity of Manjushri, there are different tendencies. There is a tendency for Manjushri to be a god who gathers auspiciousness, wealth and wealth. It also tends to mean that Manjushri only represents the wisdom of Buddhism.

This article does not further discuss the various tendencies that appear in the study of Manjusri's strength, but mainly discusses the wisdom of Manjusri's wisdom from the perspective of value rationality. Manjusri wisdom is not born out of thin air, but it is not born. It is obvious that this wisdom contains profane wisdom and breaks away from it. The profane wisdom is inspired by the troubles of the world. The specific troubles such as life and death, marriage and family, the universe and so on. Because they are from the world, the wisdom of Manjusri is more grounded and can provide us with new ideas and methods. If we all can learn wisdom in the wisdom of Manjusri, dialectically look at the problem, and understand the inner truth of things, we can solve the problems of life and enjoy happiness from it.

\section{THE STUDY OF MANJUSRI WISDOM BY MODERN SCHOLARS}

However, "Manjusri Wisdom" really entered the academic field as a new academic concept. Because of the continuous research and promotion of $\mathrm{Mr}$. Xiao, he played a very important role. He introduced philosophical hermeneutics to systematically construct it.

You Xiangzhou used the two classics of The Laws without Laws and The Vimalaki Sutra translated by Kumarajiva as the main scope. The following ten points were mainly discussed in the Manjusri method: First, cutting in from "deep view of the jurisprudence" ; second, the concept of life coexisting with the karma; third, the righteous thoughts as the foundation of spiritual practice; fourth, the entry of the second method; fifth, the concept of repairing by false; sixth, living and practicing -- into the sound of the door; seventh, that is, trouble and evidence of Bodhi; eighth, into all the Buddha's door; ninth, easy to use; tenth, do not move the door. It can be seen that it 
is precisely because of Manjusri's method that Manjusri wisdom is different from Buddha wisdom. This is similar but different, because the "wisdom" of Manjusri wisdom can be understood from the following two aspects: first, Buddha represents wisdom, second, it is the wisdom of Manjusri style, the wisdom of Manjusri law, the former is the method of wisdom, and the latter is the purpose of wisdom. Therefore, in a narrow sense, Manjusri wisdom is a kind of "method" wisdom. In a broad sense, this is both the wisdom of the "result" and the wisdom of the "method." The wisdom that symbolizes the Buddha is also prajna.

However, there is a reason why the wisdom of Manjusri has never been popularized by its own value in Chinese long history. Manjusri wisdom originated in India. But at that time, due to the repression of Guanshan,as the introduction of Manjusri wisdom into China, Confucianism was deeply rooted in people's minds, and at this time the Chinese people were in a state of misery and the persecution of war. Although the introduction of Indian Buddhism wisdom has brought certain influence, it has not been supported and promoted by the upper class scholars, resulting in the spread of Manjusri wisdom in a small scope. The failure to popularize Manjusri's wisdom was caused by the background environment at the time. Feng Qiaoying made a detailed examination of the introduction and spread of Manjusri's wisdom in China. He believed that Manjusri wisdom began in the Northern Wei Dynasty and flourished in the Tang Dynasty, from the Five Dynasties until the Song Dynasty. It lasted for a long time. During the Yuan, Ming and Qing Dynasties, due to the introduction of Lamaism, it become a bond of national unity."

There were still recurring phenomena of chinesization and spread of Manjusri wisdom in Chinese culture. In the period of Wenwei and Xiaowen in the Northern Wei Dynasty, the wisdom of Manjusri was spread to a certain extent, bringing the great prosperity of Wutai Mountain in Shanxi Province. The status of Wutai Mountain as the Manjusri dojo began to be established during the Tang Dynasty, when Emperor Taizong Li Shimin and Wuhou Wu Zetian were in power. In the Qing Dynasty, the emperor minister also repeatedly went to Wutai Mountain for pilgrimage, and there was a Kang-Qian flourishing, and the national strength was unprecedentedly prosperous, so that the people of neighboring countries looked up to China. Among the various dynasties, Manjusri's "prajna vaginal wisdom" has been spread to a certain extent, but there were also the literary wisdom during the dynasty that has not received attention, and has been degraded to the people and has not been widely disseminated. Throughout China's history, it is not difficult to find that if the rulers make great efforts to create a prosperous country, Manjusri wisdom must be correspondingly spread. On the contrary, when Manjusri wisdom was depressed, it couldn't be spread in the world, and even it was misunderstood and distorted. The departure from the Bodhisattva path means that it must be the decline of Chinese dynasties.

\section{THE NEW ERA OF THE FOLLOWING WISDOM}

In the history of China, social wealth has increased with the development of society. There have been no effective methods for the management of private property in the past dynasties. Therefore, corruption in each dynasty would be serious in the middle and late stages, and China has been since ancient times, the inter-frame structure and the administrative efficiency has become lower and lower, the people's lives were miserable, the social unrest has intensified, thus the decline followed. All dynasties in China since ancient times have bound and controlled the people with ideology and moral standards. The ancient uprising always wanted an excuse that was scrutiny. Therefore, when social unrest and the internal struggle of the court threaten the barriers constructed by this ideology, the system formulated by the state will lose its effectiveness and the chaos will intensify. At this time, the rulers continued to exercise dictatorship and constrained the people's thoughts. The people struggled to cope with the high taxes, which made the material insufficient, and they also did not receive spiritual satisfaction. Over time, a vicious circle was formed. It led to the inevitability of the decline of the dynasty. It can be seen that the satisfaction of the conscious world can help the ruler and also can bring a heavy disaster to the ruler.

Manjusri wisdom is spread among the people, and its transcendence wisdom occupies a position that cannot be ignored, because it is more likely to resonate with the creative wisdom of the people. The relationship between transcendental wisdom and intellectual wisdom is actually the relationship between value rationality and instrumental rationality. When value rationality prevails, it will dominate the instrumental rationality, which is what the people call "smart use in the right path." and the society will develop in an orderly manner. If not, society will be criticized and chaotic. In today's multi-polar world, there are endless problems, such as world environmental issues, ecological problems and international terrorism, which are not unrelated to the expansion of instrumental rationality.

When it comes to the significance of Manjusri wisdom to the new era, it is necessary to start with the interpretation of justice and the construction of institutions. From the perspective of the social sciences, institutions generally refer to a social structure that regulates individual actions by rules or modes of operation. These rules contain the value of society, and its operation recognizes the order of a society. The system is a kind of existence that people have purposes to construct. The existence of the system will have value judgments in it, which will regulate and influence the behavior of people in the system. Without the norms and guidance of the system, it is difficult to carry out practical exploration and it is difficult to promote replication. The reform of the system and mechanism will not be completed overnight, and the system construction cannot be completed overnight. Instead, it should adhere to the problem orientation, embody the stage characteristics, and grasp the current main contradictions and the most prominent problems. "In the process of promoting the construction of the system, the problems which often arise in the work must be found in the law, and the recurring problems must be found in the system." Through the wisdom of Manjusri, the system can 
be effectively integrated at a higher level. . In a system of several institutions, the interaction and actual operation of the system constitutes a mechanism. A good mechanism can do more with half the effort. A bad mechanism makes bad guys worse and creates a vicious circle. In the past, we were also studying systems and formulating systems, but often because the innovative research of the system was not carried out from the perspective of Manjusri wisdom, the system has been operating under the old model.

In recent years, Mr. Xiao Limin has applied the method of philosophical hermeneutics, and at the same time put forward the "Manjusri wisdom philosophy" in combination with the judgment thought. Systematic combing, systemic construction, novel interpretation and modernization transformation of "Manjusri wisdom philosophy" have laid a solid foundation for the formation of the next generation of wisdom culture in the new era. It also gives today's socialism to realize China's great rejuvenation. Dreams provide a different kind of value reference, which has a rich ideological content, so the wisdom of the new era can still shine brightly.

"Manjusri wisdom" can make people achieve unity in mind and practice, and can lead to spiritual realm and secular environment, complete a personality integration and spiritual mode transformation in the true sense, with a moral subject that stands proudly, returns to human nature, selfimprovement. Therefore, Manjusri wisdom still has important value and significance in China's socialist construction in the new era. From Xiaojianda, Buddhist Buddhism is still one of the living forces for China to achieve great rejuvenation. Ideological work is an extremely important task of the party. Since the Third Plenary Session of the Eleventh Central Committee of the Party, our party has always insisted on taking economic construction as the center and concentrating on bringing economic construction up and bringing people's lives up. As long as there is no fundamental change in the domestic and international trends, we must not and should not change the focus on economic construction. Adhere to open development, cooperative development, and win-win development, develop ourselves through the struggle for a peaceful international environment, and maintain and promote world peace through its own development, continuously improve China's overall national strength, and continuously enable the broad masses of the people to enjoy the peaceful development benefits, constantly consolidating the material and social foundations of the path of peaceful development. Enhance the propaganda of voluntary tree planting, protect trees in strict accordance with the law, continuously create better ecological conditions for the Chinese dream of building a well-off society in an all-round way and realizing the great rejuvenation of the Chinese nation. Under the guidance of Manjusri wisdom, Buddhism is conducive to the problem of the imbalance of social class mentality, and exerts the characteristic psychological adjustment function of Buddhism; it is beneficial to Buddhism to further develop its charity, ethical self-discipline, folklore, and ecological environment, protect and maintain social functions such as social stability.
As one of the most preserved areas of Buddhist cultural heritage, Wutai Mountain, Han Chuan and Tibetan Buddhism, as well as Chinese Buddhism, are gathered here. Overseas Chinese and many Japanese, Korean and even Nepalese people come here to worship Manjusri. As a pure land ancestral home of China and Japan, Shanxi Xuanzhong Temple was initially restored in April 1973. At the time, accompanied by Zhao Puchu and Zhengguo Master, the Japanese Buddhist delegation visited the Xuanzhong Temple in Shanxi. It was the first voice of China's opening to the world. From another perspective, Buddhism can play a role in maintaining the peace of all countries.

\section{CONCLUSION}

These all reflect the many social functions of Buddhism that contains to maintaining social stability, safeguarding national unity and motherland reunification, and strengthening international cultural exchanges. Under the current situation of vigorously promoting cultural construction, Manjusri wisdom can still shine brightly in the present, and hope that more people, whether scholars or civilians, can calm down and study and research the wisdom of Manjusri, and realize the greatness of the Chinese nation for building socialism, which have important value to bring out a rejuvenation of the Chinese nation.

\section{REFERENCES}

[1] Zhao Puchu, Buddhist Interpretation [M] Beijing: Religious Culture Press. (In Chinese)

[2] Deng Zimei. Manjusri - the symbol of Eastern wisdom [N]. China National News, 2004 - 09 - 03. (In Chinese)

[3] The Buddha said that the first stern Yan Sanjing (Vol. 2) [A]. Dazheng Tibetan (Volume 15) [M]. Taipei: Xinwenfeng Press, 2000:644a. (In Chinese)

[4] Yang Zengwen. The nationalization of Maitreya classics and Maitreya beliefs [J]. Maitreya, 2009 (1). (In Chinese)

[5] Yinshun Master. The origin and development of the early Mahayana Buddhism [A]. The Complete Works of Buddhist Inscriptions by Yin Shun (Volume 16) [M]. Beijing: Zhonghua Book Company, 2009. (In Chinese)

[6] Jing Tianxing; From "Manjusri Mantra" to "Manjusri Wisdom" Reflections on the Research Method of "Manjusri Shili" "Journal of Zhangzhou Teachers College"-2013-0830. (In Chinese)

[7] Manjushri - the symbol of Eastern wisdom _ Alaya consciousness 2014. (In Chinese) 